\title{
- APOKALIPSA IZ SVEMIRA: KOSMOLOŠKA EVOLUCIJA U PRIČI „ZVEZZDA“ H. DŽ. VELSA
}

\author{
GORAN PETROVIĆ ${ }^{1}$ \\ Filološki fakultet \\ Univerzitet u Beogradu \\ Srbija
}

U ovom radu se analizira naučno-fantastična priča „Zvezda" H. Dž. Velsa, pri čemu se u središte analize stavlja naučna misao astronoma Laplasa, čiji je model bezbožne kosmološke evolucije utro put pesimizmu poznog devetnaestog veka. Vels, kao jedan od prevrednovatelja tehnokratskog optimitizma, viktorijansku buržoaziju napada Laplasovim kosmološkim evolucionizmom, ili konkretnije, idejom da sudari nebeskih tela igraju neizostavnu ulogu u razvitku svemira. Pri tome, planeta Zemlja se uzima kao ničim privilegovana u sveukupnom kosmičkom ustrojstvu, te se tako opovrgava hrišćanski i deistički antropocentrizam. Analizom, koja poseban naglasak stavlja na naučnu utemeljenost "Zvezde", dolazi se do zaključka da je Vels ovim delom uspostavio osnovu za sve buduće umetnike koji će maštati o mogućnosti sudara zvezde sa Zemljom, što je, u naučnom pogledu, malo verovatan, ali ne i nemoguć događaj. Zatim, izvlači se zaključak o izuzetnosti pripovednog jezika u priči, a takođe se i pretpostavlja da je Vels ovom pričom u određenoj meri inspirisao tzv. „efekat praćke“, pojavu koja će u kasnijim decenijama naći primenu u svemirskom inženjerstvu. Kao sveobuhvatni tematski zaključak nameće se uvid u malenkost čoveka spram beskrajnog i nasilnog kosmosa.

Ključne reči: H. Dž. Vels, Laplas, evolucija, kosmos, prevrednovanje, Zemlja, zvezda, katastrofa.

1 Kontakt podaci (Email): gphwchamp@gmail.com 


\section{UVOD}

Kako u svojoj eminentnoj studiji o ranom delu H. Dž. Velsa navodi Bernard Bergonzi, poslednja decenija devetnaestog stoleća odlikovala se prevrednovanjem vrednosti (Bergonzi 1961: 1-22). Kada je reč o etičkim i spoznajnim vrednostima viktorijanske epohe, fin de siècleje podrazumevao dvobočni udar na buržoaziju - sjedne strane, čudan i licemerni spoj hrišćanske duhovnosti i progresivističkog materijalizma napadale su estete poput Oskara Valjda (Oscar Wilde, 1854-1900) i Obrija Birdslija (Aubrey Beardsley, 1872-1898), dok su nasuprot njima, naizgled čvrstu građevinu konzervativnih ideja podjednako podrivali i pisci naučnog usmerenja. U potonjoj grupi mislilaca, naročito se isticao H. Dž. Vels (Herbert George Wells, 1866-1946).

Stekavši prvu slavu antropološki i kosmološki pesimističnim romanom Vremeplov (The Time Machine, 1895), ovaj nekadašnji student T. H. Hakslija (Thomas Henry Huxley, 1825-1895) mnogobrojnim je romanima i pripovetkama i u narednim godinama nastavio da napada samodovoljnost i neizmerni optimizam viktorijanske buržoazije. U tim svojim delima koje je sam nazivao "naučnim romansama", a koje su preteča naučno-fantastičnog žanra, Vels se obilato služio savremenim naučnim saznanjima koja su, počevši od poznog osamnaestog veka, sve glasovitije podsećala da za tehnokratski optimizam Frensisa Bejkona (Francis Bacon, 1561-1626) nema nikakvih osnova. Spoznajne i etičke istine Viktorijinog razdoblja ovaj je autor preinačavao ponajviše na polju darvinističke biologije; ipak, i bogato zaveštanje astronomske discipline davalo mu je podsticaja za svrgavanje optimizma.

Jedno od najuspelijih, astronomijom inspirisanih dela Velsovih, svakako je kratka priča „Zvezda" ("The Star") u kojoj se opisuju kataklizmične posledice što ih na Zemlji ostavlja blizak prolazak nekakve zvezde. Ovo delo, koje je prvi put objavljeno decembra 1897, Bergonzi je naročito hvalio zbog njene „izvrsne pripovedne veštine“ i „živopisnih, lepo raspoređenih, slika” (Bergonzi 1961: 74). Međutim, iako hvali Velsovo umeće da dočara utisak o sveopštoj apokalipsi, ovaj renomirani kritičar ne posvećuje mnogo pažnje naučnoj utemeljenosti ovoga dela. S tim u vezi, a nastojeći da dopunimo Bergonzijevu kritiku „Zvezde“, ovaj će rad imati za cilj da pokaže kakvu je ulogu u postanku Velsove priče igralo astronomsko znanje koje je, do završne decenije devetnaestog veka, već bilo dostiglo značajne visine. U tu svrhu najpre treba ukratko predstaviti misao Laplasa, naučnika koji je značajno uticao na Velsa.

\section{LAPLAS KAO PREVREDNOVATELJ NJUTNOVOG DEIZMA}

Pjer Simon Laplas (Pierre-Simon Laplace, 1749-1827), francuski matematičar i astronom, $u$ istoriji će nauke ostati upamćen kao tvorac nebularne hipoteze, prema kojoj se Sunčev sistem, putem rotacije i gravitacionog sažimanja, formirao iz nekakve hladne magline. Ta rotirajuća i sažimajuća proto-maglina, koja se usled sve bržih pokreta zagrevala, na kraju je po zakonu centrifugalne sile iz sebe izbacila lake gasove, koji su se docnije, tokom duge evolucije, hladeći se stvrdnjavali i postajali planetama. Sateliti su, prema ovoj teoriji, postali od planeta na isti način na koji su planete postale od proto-magline, tj. Sunca (Димитријевић/Томић 2002: 108). 
Iako Laplas nije prvi predložio model kosmološke evolucije, koji se suštinski razlikovao od za dugo vremena preovladavajuće kosmogonije Staroga zaveta, njegova je ideja bila prva istinski revolucionarna - jer je bila lišena deističke premise o postojanju božanskog tvorca koji se, regulišući povremene nepravilnosti u kretanju nebeskih tela, stara o večnom postojanju Zemlje i čovečanstva. Ovakvo poimanje činilo je srž kosmogonijskog modela Isaka Njutna (Isaac Newton, 1642-1727), najčuvenijeg deiste i tvorca klasične mehanike, koji je verovao daje priroda časovnik što ga je bog na postanju navio i ostavio da, tek uz povremeni nadzor, otkucava po zakonima fizike. Laplas je, dakle, prvi naučnik koji je nedvosmisleno pisao da nikakva natprirodna svemudrost ne upravlja kosmosom, da uočene nepravilnosti u kretnjama nebeskih tela (planeta, kometa, meteora itd) mogu ugroziti i Zemlju, baš kao i bilo koje drugo telo (Laplace 1830: 332-333, Schechner 1997: 211-213), te da to što ljudi, kao jedina bića koja umeju da misle, sebi daju privilegovano mesto u vasioni, ne znači da je antropocentrizam ispravno ontološko gledište. Na kraju krajeva, „Sunčev sistem [...] samo je beznačajna tačka u kosmosu", te „ako pratimo istoriju napredovanja i grešaka ljudskog uma, primetićemo da se konačni uzroci vazda povlače, srazmerno sa širenjem granica našeg znanja" (Laplace 1830: 333). Pod tim konačnim uzrocima Laplas je podrazumevao tajnu o pokretaču svega postojećeg, tj. božanskom tvorcu, čije se postojanje ne može dokazati (Laplace 1830: 333).

Dakle, zašto je Sunčeva proto-maglina uopšte počela da se rotira, nikada nećemo saznati, a svako božanstvo, bez obzira na to da li je reč o onom koje nad čovekom bdi čudotvorstvom, kao u izvornom hrišćanstvu, ili ono koje to čini prirodnim zakonima, kao u deizmu, puki je pokušaj da se svemir antropocentrizuje, a ljudska misao načini optimističnom. S druge strane, istinski naučnik koji dosledno prati Bejkonove posmatračke i induktivne metode i koji se upravlja isključivo razumom, ne boji se da kaže istinu, kakva god ona bila - a istina P. S. Laplasa je, kao i istina H. Dž. Velsa, bila suštinski neantropocentrična i pesimistična.

\section{3. „ZVEZDA“": KOSMIČKA APOKALIPSA}

Velsova „Zvezda“ predstavlja umetničku interpretaciju kolizionog događaja koji je Laplas dopuštao u daljoj budućnosti i koji je, kako je ustanovljeno u poznom osamnaestom i ranom devetnaestom veku, u prošlosti imao učešća u razvoju kosmosa i planete Zemlje (Schechner 1997: 211; Clerke 1887: 89-96). Premda Velsova priča nije prva umetnička obrada laplasovskog zaokreta u shvatanju Zemljinog mesta u svetu, ona na određeni način ipak jeste inovativna. Naime, roman Smak sveta (La Fin du Monde, 1893/4) Kamija Flamariona (Camille Flammarion, 1842-1925) opisuje katastrofalne posledice udara komete u Zemlju (Clute/Nicholls 1993: 432; Bergonzi 1961: 74), dok Velsova pripovetka u ulozi uništitelja ima zvezdu - a udar zvezde je za razliku od udara komete, kako objašnjava Piter Nikols, krajnje neverovatan događaj, „nešto što bismo primetili mnogo vekova pre [samog događaja]" (Nicholls 1983: 113). Međutim, uprkos maloj mogućnosti takve kolizije, ona i dalje zaokuplja pažnju naučno-fantastičnih pisaca i kinematografa (Nicholls 1983: 113), pa se u tom smislu Vels može smatrati pionirom ovakvog scenarija u umetnosti. 
Priča počinje u novogodišnji dan, na samom početku dvadesetog veka, tako što iz tri opservatorije stiže obaveštenje da su pokreti Neptuna, „najspoljnije od svih planeta što se okreću oko Sunca, postali veoma nepravilni" (Wells 2007). Na samom početku pripovedač uspostavlja analogiju sa stvarnom istorijom nauke, ali i postavlja antitezu progresivističkoj misli viktorijanskog doba koja je od dvadesetog veka očekivala potvrdu i dalji razvoj postignutog napretka. Takođe, pisac nas u samom povoju priče obaveštava i o ništavnosti čoveka u svemiru, ništavnosti koja potkraj osamnaestog veka beše uzrela kao antipod mistici religije:

Malo je ljudi bez ikakve naučne obuke koji mogu shvatiti ogromnu izolovanost Sunčevog sistema. Sunce sa svojim tačkicama od planeta, prašinom planetoida i neprimetnim kometama, pliva u praznom beskraju koji se gotovo ne da ni zamisliti. Iza orbite Neptuna nalazi se svemir, prazan koliko je ljudsko oko uzmoglo da zapazi, bez toplote, svetlosti i zvuka, sušta praznina, na dvadeset miliona puta milion milja. To je najmanja procena rastojanja koje se ima preći pre nego što se dospe do najbliže od svih zvezda. I izuzev nekoliko kometa manjih od najtanjeg plamena, nikakva materija nikada u ljudskoj istoriji nije prešla ovo more svemira, sve dok se na početku dvadesetog stoleća nije pojavio ovaj čudni potukač. Beše to velika masa tvari, glomazna, teška, što bez upozorenja juri kroz crno tajanstvo neba u blještavo sunce. (Wells 2007)

Pored neantropocentrične istine o kosmosu, Vels nam, dakle, pruža i prvi fizički opis „uljeza“. Već se u veličini zvezde i njenom nemaru za čovekovu samovažnost nagoveštava surova apokalipsa, jer potukač očigledno nema nameru da traži dozvolu za ulazak u Sunčev sistem, nema nameru da poštuje granicu koju je čovek sam sebi dao za pravo da ucrta.

Taj zvezdani džin, što je hitajući ka Suncu postajao sve krupniji i blistaviji, sve dok ga na dnevnom, a naročito noćnom nebu, nisu golim očima mogli ugledati i laici, četvrtog je januara udario u Neptun, povukavši ga u „plamenu smrt” (Wells 2007). Usled sudara zvezda se, uz bljesak, sa Neptunom stopila u "jednu užarenu masu", što su mnogi posmatrači, a naročito mornari koji ionako povazdan gledaju u nebo, dočekali sa oduševljenjem (Wells 2007). Pri opisu doživljaja ove svemirske katastrofe u opservatorijama (gde se ona mogla jasnije videti), pisac ukazuje na to sa kolikim žarom astronomi, ljubitelji tamnog nebeskog svoda, premda ni ne sluteći kojom će tačno putanjom zvezda proći, ǐ̌čekuju jedan nesvakidašnji kosmički fenomen: „U stotinama opservatorija ushićenost je bila potisnuta, ushićenost što se uzdizala gotovo do urlika, dok su dva udaljena tela zajedno jurila; i svi su žurili tamo-amo, skupljajući fotografske aparate i spektroskope, te ovaj uređaj te onaj, kako bi zabeležili ovaj zadivljujući prizor, uništenje jednog sveta" (Wells 2007).

Entuzijazam, dakle, uprkos približavanju zvezde nejenjava, iako je prisustvo jednog tako divovskog objekta u svemiru moralo u naučničkom umu, kakav je astronomski, izazvati nekakvu bojazan. Osim toga, u umovima neukih ljudi, širom evropske i afričke obale, već su, po prvom viđenju tog "malog, okruglog, jasnog, blistavog diska” toga jutra, počele da kolaju priče 0 „ratovima i kugama što ih nagoveštavaju ti vatreni znaci na nebesima" (Wells 2007). Međutim, ono što je izmaklo astronomima, nije jednome 
profesoru matematike, koji nakon četiri duge noći neprestanog rada, dolazi do zaključka da će zvezda na svom putu, ako ne udariti u Zemlju, a onda barem protutnjati tik uz nju - što u oba slučaja znači kataklizmu.

U liku matematičara sadržana je jedna od glavnih ideja sveukupne Velsove spisateljske misli, a to je ideja o naučnicima kao jedinim istinskim poznavaocima istine, pa samim tim i jedinim herojima. Profesor matematike, slično Blezu Paskalu (Blaise Pascal, 1623-1662), velikom slobodoumniku sedamnaestog veka, čije je slobodoumlje na koncu ipak moralo ustuknuti pred silom Katoličke crkve, crpi nesalomivu snagu iz spoznaje o svemoći sopstvenog uma: „Gledao ju je [zvezdu] kao što se u oči gleda kakav hrabar neprijatelj. 'Možeš da me ubiješ,' rekao je nakon što je oćutao. 'Ali ja te držim kao i čitav svemir u tom pogledu - u stisku ovog malog mozga. Neću se promeniti. Čak ni sada" (Wells 2007).

Čovek je, dakle, slabašan i ništavan pred beskonačnošču kosmosa, koji ni na koji empirijski način ne odaje utiska o božjem prisustvu, te je stoga jedina čovečja uteha u njegovoj sposobnosti da misli i da mišlju taj kosmos poima. Spoznaja, to je jedini čovekov ponos, jedina pobeda što je "misleća trska" ikada može izvojevati u borbi sa beslovesnom i ravnodušnom vasionom. Svestan mentalni prkos besmislu do samog kraja jedini je način da se ostvari filozofska pobeda, jer naučna, ateleološka istina vredi više od religiozne, teleološke samoobmane.

Ovakav profesorov stoički stav prema dolazećoj zvezdi donekle je sličan stavovima naučno neobrazovanog pučanstva. Naime, već smo pomenuli pokušaje da se neobične nebeske pojave pokušavaju objasniti kao božanske poruke ljudima, najčešće o skoroj nesreći. Ovakvo sujeverno shvatanje kometa, koje je do sedamnaestog veka bilo jedino važeće (Schechner 1997: 220), Vels, kao veliki znalac istorije, nije propustio da prikaže kao paniku koja se usled sve jarkijeg blještavila približavajuće zvezde širi među narodima Evrope. Međutim, i pored sve svoje predskazateljske ispravnosti, zabrinuti povici „Jarkijaje!" $\mathrm{i}$ „Bliži se!" (Wells 2007), ipak su samo izraz prehominidske opreznosti prema nepoznatom kao strategije održanja vrste, te se kao takvi ne mogu meriti sa mirnim i racionalnim uvidom jednog posvećenog matematičara.

Pravo neznanje u poimanju približavajuće zvezde najupečatljivije pokazuju „misleći“ predstavnici buržoaske ideologije progresa, kao na primer crkvene institucije i štampa, koji ocenivši izveštaj profesora matematike kao pokušaj samoafirmacije, tvrde da je sudar zvezde sa Zemljom nemoguć samim tim što se nikada u ljudskoj prošlosti nije dogodio:

Novinske štamparije su huktale cele noći, a mnogi sveštenik u ovoj ili onoj crkvi nije svoju svetu zgradu hteo da otvori za širenje nečega što je smatrao budalastom panikom. Novine su insistirale na lekciji od hiljadite godine - jer i tada su ljudi predviđali smak. Ta zvezda nije zvezda - već običan gas - kometa; čak i da jeste, zvezda ne može nikako da udari zemlju. Za tako nešto nema presedana. Zdrav razum je i dalje svuda bio u snazi, kritičan, podsmevački, pomalo sklon da progoni tvrdoglave strašljivce. (Wells 2007)

Međutim, profesorovi proračuni se ipak obistinjuju, te zvezda, noseći Neptunovu masu sa sobom, stupa u gravitaciono polje Jupitera, najveće od svih Sunčevih planeta. 
Usled međusobne privlačne sile između ova dva krećuća tela, Jupiterova putanja se menja postavši još elipsoidnija, dok se zvezda, umesto pravo ka Suncu, zapućuje ka Zemlji. Ova promena pravca, koja se zbiva šestog dana od početka pripovesti, zasnovana je na nepravilnosti u kretanju planeta i kometa koju je zapazio još Njutn i zbog koje je, suprotno Lajbnicu (Gottfried Wilhelm Leibniz, 1646-1716), tvrdio da bog nije stvorio tako savršen svet da bi ga po stvaranju naprosto mogao ostaviti da radi po mehaničkim zakonima, već je povremeno morao i još mora da čudima ispravlja aberacije (Macey 1994: 662; Laplace 1830: 332).

Samo, Vels u „Zvezdi" ne govori o malom međusobnom uticaju nebeskih tela na pravac kretanja, kako je pisao Njutn, već veoma velikom, što možda postavlja temelj za takozvani „efekat praćke“ kojim će se u budućnosti služiti naučnici. „Efekat praćke“, inače, u svemirskom inženjerstvu podrazumeva korišcenje gravitacionog polja i kretanja nebeskih tela radi promene brzine i pravca vasionske letelice, kao i radi uštede goriva (Gravity Assist 2018). Iako nemamo pouzdanih podataka da je Vels direktno podstakao gore opisani razvoj primenjene nauke, ipak je nepobitna sličnost između fiktivne zvezde koja zaobilazi Jupiter i, na primer, američkog Vojidžera 1 (Voyager 1), koji je 2017. na putu ka izlasku iz Sunčevog sistema za promenu pravca, osim Jupitera, iskoristio i Saturn (Gravity Assist 2018). Stoga bi se i u slučaju „efekta praćke”, kao i u slučaju svemirskog putovanja uopšte, Vels možda mogao nazvati prorokom, jer kako je jednom izjavio Artur Klark (Arthur C. Clarke, 1917-2008): „Većini tehnoloških ostvarenja prethodili su ljudi koji su o njima pisali i maštali [...] Siguran sam da ne bismo imali ljude na Mesecu da nije bilo H. Dž. Velsa i Žila Verna" (Jonas 2008).

Uglavnom, Velsova zvezda, nakon izlaska iz Jupiterovog gravitacionog polja, pet dana putuje do Zemlje, što je, kako pripovedač saopštava, daleko sporije od brzine kojom bi se kretala da nije bila usporena Jupiterovom gravitacijom. Dakle, jedanaest dana od početka priče o poremećenom kretanju Neptuna trebalo je zvezdi da stigne do treće po redu Sunčeve planete i već sledeće noći otpočinje kataklizma; jer zvezda je ušla u Zemljino gravitaciono polje.

Prva strada Amerika, na čijem istoku (u dolini Sent Lorensa, u Virdžiniji i Brazilu) zvezda, sada veličinom gotovo jednaka Mesecu, prouzrokuje „treperavu ljubičastu grmljavinu i nezapamćeni grad" (Wells 2007). U Manitobi (Kanada) pak, zbog naglog porasta temperature, dolazi do masovnog otapanja snega i leda, kao i do posledičnih poplava u unutrašnjosti Severne Amerike. Argentinsku obalu Atlantika preplavljuju morski talasi, dok od Arktika do Ognjene zemlje čitavi kontinent pogađaju snažni zemljotresi. Stambene zgrade se urušavaju, mnogo ljudi strada i od vode i od zemljotresa, a najkatastrofalniji prizor je u Ekvadoru gde je „[Č]itava strana Kotopaksija [...] skliznula u jednom velikom potresu, a lava je gromoglasno pokuljala tako visoko i široko i brzo i tečno da je u jednom danu stigla do mora" (Wells 2007).

Zatim zvezda putuje iznad Pacifika da bi i širom istoka posejala smrt. U opisu kataklizme u Aziji sreću se neki od najlepših odlomaka Velsove proze:

Tako je zvezda, sa bledim mesecom iza sebe, marširala Pacifikom, prišivala gromovite oluje kao porub kakvog ogrtača, a narastajući talas što se za njom gomilao, penušav i radostan, plavio je ostrvo po ostrvo, čisteći ih od ljudi. Sve dok napokon nije došao taj talas - u zaslepljujućem svetlu i s dahom pećnice, došao 
brz i grozan - zid od vode, visok petnaest metara, grmeći gnevno - na duge obale Azije i nagrnuo unutra plaveći kineske ravnice. Neko je vreme zvezda, sada toplija i veća i svetlija od sunca u svojoj snazi, nemilosrdnom jarkošću pokazivala prostranu i mnogoljudnu zemlju; varoši i sela sa njihovim pagodama i drvećem, drumovima, širokim obrađenim poljima, milionima neispavanih ljudi koji bespomoćni i užasnuti zure u užareno nebo; a onda se, tih i sve glasniji, začuo šum poplave. (Wells 2007)

Ovakav jezik, kako smatra Bergonzi, po lepoti suviše ne zaostaje čak ni za čuvenim opisom beživotne Zemlje u pretposlednjoj glavi Vremeplova (Bergonzi 1961: 74). Originalnim metaforama, apokaliptičnim tonom i tečnim pripovedanjem Vels iz slike u sliku pojačava utisak o užasu, o sudnjem danu, o konačnom sumraku čovečanstva. Naročito je sablastan opis katastrofe u istočnoj, jugoistočnoj i južnoj Aziji u kome izuzetan autorov osećaj za prostor postiže utisak o sveobuhvatnosti užasa kojim se zvezda obrušila na ovaj deo sveta:

Kina je bila obasjana blještavom belinom, ali iznad Japana i Jave i svih ostrva istočne Azije velika zvezda je bila lopta tamno crvene vatre zbog pare i dima i pepela što su ih vulkani, pozdravljajući njen dolazak, izbljuvavali. Iznad je bila lava, vreli gasovi i pepeo, ispod ključajuća poplava, a čitava zemlja se njihala i romorila od zemljotresa. Uskoro su se praiskonski snegovi Tibeta i Himalaja topili i slivali niz desetine miliona produbljujućih, sustičućih kanala, na ravnice Burme i Hindustana. Zeleni vrhovi indijske džungle goreli su na hiljadu mesta, a pod žurnim vodama oko stabljika bile su tamne stvari što su se još uvek slabašno borile i odslikavale kao krv crvene jezike vatre. A mnoštvo muškaraca i žena je u bezglavoj zbunjenosti bežalo niz široke rečne tokove ka toj poslednjoj čovekovoj nadi - moru. (Wells 2007)

Uistinu, jeziva slika istovremenog divljanja vatre i ključajuće vode, koja donekle podseća na hrišćansku viziju mučiteljskog pakla. Ta jezivost, koja je kao roditeljski gen što ga je gotski roman preneo na svoj kćerku, naučnu fantastiku (Aldiss 1973: 8), ovde se, za razliku od gotskih misterija, tiče čitavog čovečanstva jer, kao što je Isak Asimov (Isaac Asimov, 1920-1992), čuveni pisac i kritičar jednom izjavio, glavni lik naučne fantastike nisu pojedinci već ljudski rod (McConnell 1981: 194). Za H. Dž. Velsa se nepogrešivo može reći da kao retko koji pisac zadovoljava ovu Asimovljevu definiciju, koja, doduše, ovaj žanr, i pored velike doze tačnosti, ne opisuje baš sasvim precizno (McConnell 1981: 194).

Međutim, posle višečasovnog pustošenja, apokaliptična se sablasnost svršava. Kosmički potukač što je silan i obestan za manje od dve sedmice doputovao sa ivice Sunčevog sistema Zemlju nije udario, već samo protutnjio pored nje, te se, udarivši u ogromno Sunce, zaustavio i postao delom Sunčeve mase. Mesec se, poremećen letom zvezde, odaljio od Zemlje i sada mu je, umesto trideset, trebalo osamdeset dana da obavi ciklus svojih mena.

Čovečanstvo je platilo skup ceh nepredvidivosti "nebeske mehanike", kako je kretanje nebeskih tela nazivao Laplas. Mnoge je žrtve, i ljudske iživotinjske imaterijalne, zvezda uzela sebi za danak. Međutim, koliko god taj ceh bio skup, on je ipak neznatan u očima marsovskih astronoma, čijom se procenom ove katastrofe priča završava: 
„Uzevši u obzir masu i temperaturu projektila koji je kroz naš Sunčev sistem proleteo ka suncu [...] zapanjujuće je koliko je neznatnu štetu pretrpela Zemlja, koju je samo za malo promašio" (Wells 2007). Zemlja je, dakle, tek čestica u kosmosu, u kome ne postoji niko koga bi čovekovi jadi tištili. Velsov optimizam pred kraj dela u vidu komentara 0 boljim vremenima što su nakon zvezde usledila za "novo bratsvo" čovečanstva (Wells 2007) ne može, držimo, zaseniti pesimistični duh ove priče, jer se kao konačna poruka nameće naučna istina P. S. Laplasa, koja prilagođena Velsovom dobu vere u progres, biblijskom metaforom uzvikuje: Adam (čovek) se tehnologijom gordi, a Bog (priroda, tj. spoznaja o prirodi) ga za gordost kažnjava!

\section{ZAKLJUČAK}

Pripovetka „Zvezda“ predstavlja jedno od značajnijih Velsovih dela inspirisanih astronomijom. U njemu pisac, oslanjajući se na naučnu misao P. S. Laplasa, prevrednuje tehnokratski optimizam viktorijanskog doba. Polazeći od pretpostavke da je deizam, podjednako kao hrišćanstvo, u zabludi kada propoveda da se nekakvo božanstvo brine o večnom postojanju čovečanstva, Vels opisuje bliski kontakt Zemlje sa nekakvom zvezdom, iznenada pristiglom izvan Sunčevog sistema, usled čega na čovekovoj planeti dolazi do kataklizme. Ovo delo nedvosmisleno napada buržoasku samodovoljnostiveru u trajnu tehnokratsku utopiju, jer njime autor poručuje da je laplasovska kosmološka evolucija ravnodušna prema blagostanju čovekove vrste. U "Zvezdi" se zagovara stav da kolizioni događaji čine neizostavni deo razvitka svemira, te da od udara (kometa) nije zaštićena ni Zemlja, baš kao ni bilo koje drugo nebesko telo u vasioni. Iako Vels razmatra jedan, u naučnom smislu, gotovo nemoguć događaj, ne može se govoriti o naučnoj neutemeljenosti njegovog dela. Štaviše, Velsova, inače odlično ispripovedana priča, pionirska je u pogledu prikazivanja sudara zvezde za Zemljom u umetnosti, kao i u pogledu „efekta praćke" (ili tako barem pretpostavljamo), koji će kasnije imati veliku primenu u kosmonautičkom inženjerstvu. „Zvezda“ predstavlja jedan od primera Velsove umetničke virtuoznosti, ali i odraz duha fin de sièclea, kada je bilo uobičajeno pisati o propasti čovečanstva, budući da su astronomska evolucionistička saznanja jasno kazivala da čovek nije gospodar prirode, već puka igračka u njenim rukama.

\section{LITERATURA}

Aldiss, B. 1973. Billion Year Spree: the True History of Science Fiction. New York: Doubleday \& Company.

Bergonzi, B. 1961. The Early H. G. Wells: a Study of Scientific Romances. Manchester: Manchester University Press.

Brush, S. G. 1996. A History of Modern Planetary Physics: Fruitful Encounters. Cambridge: Cambridge University Press.

Clute, J. \& Nicholls, P. (eds). 1993. The Encyclopedia of Science Fiction. New York: St. Martin's Press. [Internet]. Dostupno na: https://archive.org/stream/ encyclopediaofsc00ies1\#page/516/mode/2up [29.05.2018]. 
Димитријевић, М. и Томић, А. 2002. Астрономија за IV разред гимназије. Београд: Завод за уџбенике и наставна средства.

Gravity Assist. 2018. [Internet]. Dostupno na: https://en.wikipedia.org/wiki/Gravity_ assist [30.05.2018].

Jonas, G. 2008. Arthur C. Clarke, Author Who Saw Science Fiction Become Real, Dies at 90. New York Times. [Internet]. Dostupno na: https://www.nytimes.com/2008/03/19/ books/19clarke.html [30.05.2018].

Laplace, P. S. 1830. The System of the World. Translated from French by Rev. Henry H. Harte. [Internet]. Dostupno na: https://archive.org/stream/ systemofworldtra02lapluoft?ref=ol\#page/332/mode/2up [27.05.2018].

Macey, S. L. 1994. Encyclopedia of Time. Book: 810, Series: Garland reference library of social science. Routledge.

McConnell, F. D. 1981. The Science Fiction of H. G. Wells. New York / Oxford : Oxford University Press. [Internet]. Dostupno na : https://archive.org/stream/ sciencefictionof00fran\#page/n5/mode/2up [30.05.2018].

Nicholls, P. (ed). 1993. The Science in Science Fiction. New York: Alfred A. Knopf. [Internet]. Dostupno na: https://archive.org/stream/scienceinscience00nich\#page/112/ mode/2up [28.05.2018].

Wells, H. G. 1898. The War of the Worlds. New York / London: Harper \& Brothers Publishers. [Internet]. Dostupno na: https://archive.org/stream/ warofworlds1898well?ref=ol\#page/n5/mode/2up [01.06.2018].

Wells, H. G. 2007. The Short Stories of H. G. Wells, 1927. Project Gutenberg Australia. [Internet]. Dostupno na: http://gutenberg.net.au/ebooks06/0609221h.html [25.05.2018].

\section{SUMMARY}

\section{APOCALYPSE FROM SPACE: COSMOLOGICAL EVOLUTION IN H. G. WELLS'S STORY "THE STAR"}

This paper analyses H. G. Wells's science-fiction story "The Star". The study is centred on the scientific thought of the astronomer Laplace, whose model of godless cosmological evolution paved the way for the late nineteenth century pessimism. Wells, as one of the critics of technocratic optimism, undermines the Victorian burgeoisie with Laplace's cosmological evolutionism or, more specifically, with the idea that collisions between heavenly bodies play an integral role in the evolution of the Universe. Apropos of that, the planet Earth is considered to be by no means privileged in the overall arrangement of the cosmos, which results in both Christian and Deist anthropocentrism being invalidated. Our analysis, which in particular stresses the scientific background of "The Star", concludes that Wells sets a precedent for all the future representations of star-Earth collisions in art, which, in scientific terms, is an unlikely but not an impossible event. In addition, it is concluded that Wells's narrative language is extraordinary, and also a guess is made that Wells, to an extent, may have inspired the so-called "slingshot effect", a phenomenon to be later on exploited in space engineering. In all- 
encompassing thematic terms, a conclusion is reached about the smallness of man against the background of the endless and violent cosmos.

KEYWORDS: H. G. Wells, Laplace, evolution, cosmos, transvaluation, earth, star, catastrophe. 